\title{
Association of kidney function with inflammatory and procoagulant markers in a diverse cohort: A cross-sectional analysis from the Multi-Ethnic Study of Atherosclerosis (MESA) Christopher Keller*1,2, Ronit Katz ${ }^{3}$, Mary Cushman ${ }^{4}$, Linda F Fried ${ }^{5}$ and Michael Shlipak ${ }^{2}$
}

\begin{abstract}
Address: ${ }^{1}$ Department of Medicine, University of California San Francisco, San Francisco, CA, USA, ${ }^{2}$ San Francisco Veterans Affairs Medical Center, General Internal Medicine Section, San Francisco, CA, USA, ${ }^{3}$ Collaborative Health Studies Coordinating Center, University of Washington, Seattle, WA, USA, ${ }^{4}$ Departments of Medicine and Pathology, University of Vermont, Burlington, VT, USA and ${ }^{5}$ Renal Section, Veterans Affairs Pittsburgh Healthcare System, Pittsburgh, PA, USA

Email: Christopher Keller* - Christopher.Keller@ucsf.edu; Ronit Katz - RKatz@u.washington.edu; Mary Cushman - Mary.Cushman@uvm.edu; Linda F Fried - Linda.Fried@va.gov; Michael Shlipak - Michael.Shlipak@ucsf.edu

* Corresponding author
\end{abstract}

Published: 5 August 2008

BMC Nephrology 2008, 9:9 doi:10.1 186/147/-2369-9-9
Received: 4 March 2008

Accepted: 5 August 2008

This article is available from: http://www.biomedcentral.com/l47I-2369/9/9

(C) 2008 Keller et al; licensee BioMed Central Ltd.

This is an Open Access article distributed under the terms of the Creative Commons Attribution License (http://creativecommons.org/licenses/by/2.0), which permits unrestricted use, distribution, and reproduction in any medium, provided the original work is properly cited.

\begin{abstract}
Background: Prior studies using creatinine-based estimated glomerular filtration rate (eGFR) have found limited associations between kidney function and markers of inflammation. Using eGFR and cystatin $\mathrm{C}$, a novel marker of kidney function, the authors investigated the association of kidney function with multiple biomarkers in a diverse cohort.

Methods: The Multi-Ethnic Study of Atherosclerosis consists of 6,814 participants of white, African-American, Hispanic, and Chinese descent, enrolled from 2000-2002 from six U.S. communities. Measurements at the enrollment visit included serum creatinine, cystatin $C$, and six inflammatory and procoagulant biomarkers. Creatinine-based eGFR was estimated using the fourvariable Modification of Diet in Renal Disease equation, and chronic kidney disease was defined by an eGFR $<60 \mathrm{~mL} / \mathrm{min} / \mathrm{l} .73 \mathrm{~m}^{2}$.

Results: Adjusted partial correlations between cystatin $C$ and all biomarkers were statistically significant: C-reactive protein $(r=0.08)$, interleukin-6 $(r=0.16)$, tumor necrosis factor- $\alpha$ soluble receptor I (TNF- $\alpha R I ; r=0.75)$, intercellular adhesion molecule-I $(r=0.2 I)$, fibrinogen $(r=0.14)$, and factor VIII ( $r=0.1$ I; two-sided $p<0.01$ for all). In participants without chronic kidney disease, higher creatinine-based eGFR was associated only with higher TNF- $\alpha$ RI levels.
\end{abstract}

Conclusion: In a cohort characterized by ethnic diversity, cystatin $C$ was directly associated with multiple procoagulant and inflammatory markers. Creatinine-based eGFR had similar associations with these biomarkers among subjects with chronic kidney disease.

\section{Background}

Higher levels of markers of inflammation, such as C-reactive protein (CRP) and interleukin 6 (IL-6), have been associated with cardiovascular disease in healthy populations [1-3]. In subjects with end stage renal disease (ESRD), inflammatory biomarkers are significantly ele- 
vated and predict poor outcomes [4-7]. In subjects with kidney disease not on hemodialysis, kidney function has been associated with markers of inflammation for creatinine-based estimated glomerular filtration rates (eGFR) below $60 \mathrm{~mL} / \mathrm{min} / 1.73 \mathrm{~m}^{2}$. Above that threshold, two studies did not find an association between eGFR and markers of inflammation $[8,9]$.

Cystatin C, a cysteine protease inhibitor secreted by all nucleated cells, is a novel serum marker for kidney disease that may better detect small changes in kidney function [10-12]. Since creatinine-based eGFR is not reliable above $60 \mathrm{~mL} / \mathrm{min} / 1.73 \mathrm{~m}^{2}$, cystatin C may be superior in detecting an association with inflammation in subjects with mild to moderate kidney disease $[13,14]$. Using cystatin C as a marker for kidney function in an ambulatory elderly cohort, all with creatinine-based eGFR $\geq 60$, we reported linear associations between cystatin $\mathrm{C}$ and five inflammatory markers: CRP, IL-6, tumor necrosis factor alpha (TNF$\alpha$ ), and two soluble TNF- $\alpha$ receptors [15]. In a cohort with known coronary artery disease, cystatin $\mathrm{C}$ was associated with both CRP and fibrinogen across the entire cohort, while creatinine-based eGFR was significantly associated with CRP and fibrinogen only for eGFR $<60$ [16].

The current study investigated the association of both creatinine-based eGFR and cystatin C with six inflammatory and procoagulant biomarkers in the Multi-Ethnic Study of Atherosclerosis (MESA), a large cohort characterized by racial and ethnic diversity. Compared with prior studies on kidney function and markers of inflammation, this study featured a population with four racial/ethnic groups, a younger mean age (62 years), no clinical cardiovascular disease, and more extensive measurements of both inflammatory and procoagulant biomarkers. In addition, a second objective of this study was to test whether the association between kidney function and multiple inflammatory and procoagulant biomarkers differed by race/ethnicity.

\section{Methods}

The MESA cohort consists of 6,814 men and women who identified themselves as white, African-American, Hispanic, or Asian (of Chinese descent). At the time of enrollment, the subjects were 45 to 84 years of age and free of clinical cardiovascular disease (CVD). Participants were enrolled from July 2000 to August 2002, and recruited from six US communities. Subjects were initially recruited using residential and telephone listings; towards the end of the recruitment period, lists of Medicare beneficiaries and participant referrals were also used to ensure an adequate number of participants. The study was approved by institutional review boards at each center, and all study participants gave informed consent.
All biochemistry assays were performed on plasma or serum drawn in the morning after an overnight fast during the initial visit and stored at $-70^{\circ} \mathrm{C}$. Cystatin $\mathrm{C}$ was measured using a BNII nephelometer on plasma specimens ( $\mathrm{N}$ Latex Cystatin C; Dade Behring Inc., Deerfield, IL) [17]. The assay range is 0.195 to $7.330 \mathrm{mg} / \mathrm{L}$, with the reference range for young, healthy individuals reported as 0.53 $0.95 \mathrm{mg} / \mathrm{L}$. Intra-assay coefficients of variation (CVs) range from $2.0-2.8 \%$ and inter-assay CVs range from 2.3 $-3.1 \%$. Serum creatinine was measured using colorimetry with a Johnson \& Johnson Vitros 950 analyzer (Johnson \& Johnson Clinical Diagnostics Inc., Rochester, NY). The CVs for serum creatinine were $\leq 2 \%$. Estimated GFR was calculated using the creatinine-based four-variable Modification of Diet in Renal Disease (MDRD) equation, which features adjustments for age, gender, serum creatinine, and black race [18]. Creatinine levels were calibrated to the Cleveland Clinic standard $\left(0.9954^{*} \mathrm{Cr}+0.0208\right)$ [19]. Lipid measurements were performed using the Roche COBAS FARA centrifugal analyzer (Roche Diagnostics, Indianapolis, IN). Low-density lipoprotein cholesterol (LDL) was calculated using the Friedewald equation [20]. Serum glucose was measured using the Vitros 950 analyzer. Urine samples for measuring creatinine and albumin were taken from a spot urine collection at the initial visit. Urinary creatinine was measured using the Vitros 950. Urinary albumin was measured using an Array 360 CE Protein Analyzer (Beckman Instruments Inc., Fullerton, CA). Chronic kidney disease was defined as eGFR < $60 \mathrm{~mL} / \mathrm{min} / 1.73 \mathrm{~m}^{2}[13]$.

CRP was measured using a BNII nephelometer ( $\mathrm{N}$ high sensitivity CRP; Dade Behring Inc.), with intra-assay CVs of $2.3 \%-4.4 \%$, inter-assay CVs of $2.1 \%-5.7 \%$, and a detection level of $0.18 \mathrm{mg} / \mathrm{L}$ [21]. IL-6 was measured by ultra-sensitive ELISA (Quantikine HS Human IL-6 Immunoassay; R\&D Systems, Minneapolis, MN) with an analytical CV of $6.3 \%$ and a detection level of $0.04 \mathrm{pg} / \mathrm{mL}$. Tumor necrosis factor alpha receptor 1 (TNF- $\alpha \mathrm{R} 1)$ was measured by ultra-sensitive ELISA (Quantikine Human sTNF RI Immunoassay; R\&D Systems) with an analytical $\mathrm{CV}$ of $5.0 \%$ and a detection level of $0.77 \mathrm{pg} / \mathrm{mL}$. Intercellular adhesion molecule 1 (ICAM-1) was measured by ELISA (Parameter Human sICAM-1 Immunoassay; R\&D Systems), with a CV of 5.0\%. Fibrinogen was measured using a BNII nephelometer ( $\mathrm{N}$ Antiserum to Human Fibrinogen; Dade Behring Inc.) with intra-assay and interassay analytical CVs of $2.7 \%$ and $2.6 \%$, respectively. Factor VIII coagulant activity was determined by measuring the clotting time of a sample in factor VIII deficient plasma in the presence of activators utilizing the Sta-R analyzer (STA-Deficient VIII; Diagnostica Stago, Parsippany, NJ), with a reported normal plasma range in the adult population of $60-150 \%$. CRP, IL-6, fibrinogen, and factor VIII were measured in the entire cohort. Intercellu- 
lar adhesion molecule-1 (ICAM-1) was measured in a total of 2,614 subjects, including all participants who enrolled before February 2003 and a subset of 1,000 participants randomly selected from the first 5,030 participants enrolled. The baseline characteristics of the random subset of participants were not significantly different from those of the entire MESA cohort. TNF- $\alpha$ R1 (995 samples) was measured in a subset of the cohort chosen randomly after $75 \%$ of the participants had been enrolled.

Participant characteristics, including demographics (age, sex, race/ethnicity); comorbid conditions (diabetes, defined as a fasting glucose $\geq 126 \mathrm{mg} / \mathrm{dL}(6.9 \mathrm{mmol} / \mathrm{L})$ or by the use of insulin or oral hypoglycemic medications, and hypertension, defined as an average systolic blood pressure $\geq 140 \mathrm{~mm} \mathrm{Hg}$, an average diastolic blood pressure of $\geq 90 \mathrm{~mm} \mathrm{Hg}$, or by the use of antihypertensive medications), smoking history, defined as ever [current or former] or never; and statin use were obtained at the enrollment visit using data from standardized questionnaires. Resting blood pressure was determined by taking three measurements with the participant in the seated position; systolic and diastolic blood pressures were recorded as the average value of the last two measurements from both the first and second study examinations. Body mass index (BMI) was calculated at the initial visit using weight $(\mathrm{kg})$ divided by height squared $\left(\mathrm{m}^{2}\right)$.

\section{Statistical Analysis}

Baseline characteristics were evaluated for statistical significance across quintiles of cystatin $\mathrm{C}$ using ANOVA or chi-square tests for trend. Histograms and $\mathrm{q}-\mathrm{q}$ plots revealed that the urinary albumin to creatinine ratio and the levels of CRP and IL-6 were skewed; therefore, logarithmic transformations of these variables were used for analysis. First, partial correlations with each of the six biomarkers were determined separately for cystatin $\mathrm{C}$ and creatinine-based eGFR, adjusting for age, gender, race/ethnicity, and BMI. Two-tailed t-tests were used for significance testing of all partial correlations. We also compared the partial correlation coefficients of eGFR and cystatin C with each biomarker after stratification by presence or absence of CKD. The two correlation coefficients were transformed using the Fisher Z-transform and the difference and a p-value were computed.

We created separate linear regression models for each of the six biomarkers. The primary predictors were either cystatin C (per SD) or eGFR by the four-variable MDRD equation, dichotomized as $<$ and $\geq 60 \mathrm{ml} / \mathrm{min} / 1.73 \mathrm{~m}^{2}$. Covariates from Table 1 were entered into the models based on their potential role as confounders due to their associations with both kidney disease and inflammation. We also determined the adjusted mean levels of each biomarker, stratified by the presence of CKD $($ eGFR $<60$
$\mathrm{mL} / \mathrm{min} / 1.73 \mathrm{~m}^{2}$ ) and by quintile of cystatin C. The mean biomarker levels were also plotted across quintiles of cystatin $\mathrm{C}$, with the y-axis scale standardized at \pm 1 SD of the overall mean of the cohort for each biomarker. For TNF- $\alpha R 1$, the $y$-axis scale was set at \pm 2 SD given the larger differences for that biomarker across quintiles of cystatin C. T-tests were used to evaluate significant differences in mean levels in subjects with and without CKD, and ANOVA across quintiles of cystatin C. We also tested for interactions of race/ethnicity with both cystatin $\mathrm{C}$ in each regression model. S-Plus (release 6.1, Insightful Inc, Seattle, WA) and SPSS statistical software (release 13.0.1, SPSS Inc, Chicago, IL) were used for the analyses. $\mathrm{P}<0.01$ was used for statistical significance because multiple comparisons were made and because a high level of power was available.

\section{Results}

The participants of the MESA study had an average age of 62 years. In the cohort, $53 \%$ of the participants were female; $39 \%$ were white, $28 \%$ African-American, $22 \%$ Hispanic, and $12 \%$ Chinese. The mean cystatin $\mathrm{C}$ level in the cohort was $0.89 \pm 0.24 \mathrm{mg} / \mathrm{L}$, and the mean creatininebased eGFR was $81 \pm 18 \mathrm{~mL} / \mathrm{min} / 1.73 \mathrm{~m}^{2}$. On average, the participants in the highest quintile of cystatin $\mathrm{C}$ were older, and more likely white and male (Table 1). Those in the highest quintile were also more likely to smoke, to have hypertension and diabetes, to have a higher BMI, to have a higher urine albumin to creatinine ratio, and to have lower levels of both LDL and HDL. Overall, the total number of subjects with CKD in the cohort was 672 $(10 \%)$.

After adjustment for age, sex, ethnicity, and BMI, cystatin $\mathrm{C}$ had statistically significant partial correlations with all six biomarkers in participants both with and without CKD (Table 2, p $<0.01$ for all). However, the associations with TNF- $\alpha$ R1 and fibrinogen were significantly stronger among participants with CKD. Similarly, creatinine-based eGFR had significant correlations with all biomarkers except ICAM-1 in subjects with CKD ( $p<0.01)$. In subjects without CKD, eGFR was associated only with TNF$\alpha R 1$. Of note, the strongest correlations for both cystatin $\mathrm{C}$ and creatinine-based eGFR were with TNF- $\alpha \mathrm{R} 1$.

Adjusted mean levels of all biomarkers except ICAM-1 were significantly higher in participants with CKD (eGFR $<60$ ) than in those without CKD (Table 3; $p<0.001$ for all). The mean levels of each biomarker in subjects without CKD were unchanged by adjustment for albumin to creatinine ratio. Adjusted mean levels for all six biomarkers increased significantly across the five quintiles of cystatin $\mathrm{C}$ (Figures $1 \mathrm{a}-\mathrm{c}$ ). The p-values for trend of the mean biomarker levels across all quintiles were less than 0.01 . For comparison, we found that the mean biomarker levels 
Table I: Baseline characteristics of MESA population by quintiles of cystatin C

\begin{tabular}{|c|c|c|c|c|c|c|}
\hline & \multicolumn{5}{|c|}{ Cystatin C (mg/L) } & \multirow[b]{3}{*}{ p-value for trenc } \\
\hline & $\begin{array}{l}\text { Quintile I } \\
\quad \leq 0.74 \\
(n=1446)\end{array}$ & $\begin{array}{l}\text { Quintile } 2 \\
0.75-0.82 \\
(\mathrm{n}=1377)\end{array}$ & $\begin{array}{l}\text { Quintile } 3 \\
0.83-0.89 \\
(n=1283)\end{array}$ & $\begin{array}{l}\text { Quintile } 4 \\
0.91-1.02 \\
(n=1359)\end{array}$ & $\begin{array}{l}\text { Quintile } 5 \\
\geq 1.03 \\
(\mathrm{n}=1285)\end{array}$ & \\
\hline & \multicolumn{5}{|c|}{ Mean \pm SD, Median [IQR], or $\%$} & \\
\hline Age & $57 \pm 9$ & $59 \pm 9$ & $62 \pm 9$ & $65 \pm 10$ & $69 \pm 10$ & $<0.001$ \\
\hline Female, $\%$ & 65 & 53 & 49 & 47 & 49 & $<0.001$ \\
\hline \multicolumn{7}{|l|}{ Race/Ethnicity, \% } \\
\hline White & 33 & 34 & $4 I$ & 41 & 44 & \\
\hline Chinese & 17 & 13 & 10 & II & 8 & \\
\hline African-American & 30 & 30 & 26 & 24 & 28 & \\
\hline Hispanic & 19 & 24 & 23 & 24 & 20 & \\
\hline Smoking History, \% & 44 & 49 & 50 & 53 & 53 & $<0.001$ \\
\hline $\mathrm{BMI}\left(\mathrm{kg} / \mathrm{m}^{2}\right)$ & $27 \pm 5$ & $28 \pm 5$ & $28 \pm 5$ & $29 \pm 6$ & $30 \pm 6$ & $<0.001$ \\
\hline Diabetes, \% & 14 & 13 & 12 & 12 & 21 & $<0.001$ \\
\hline Hypertension, \% & 34 & 36 & 43 & 50 & 64 & $<0.001$ \\
\hline $\mathrm{LDL}(\mathrm{mg} / \mathrm{dL})$ & $117 \pm 32$ & $119 \pm 31$ & $|18 \pm 3|$ & $117 \pm 32$ & $114 \pm 32$ & 0.006 \\
\hline $\mathrm{HDL}(\mathrm{mg} / \mathrm{dL})$ & $56 \pm 16$ & $51 \pm 15$ & $51 \pm 14$ & $49 \pm 14$ & $48 \pm 14$ & $<0.001$ \\
\hline Glucose (mg/dL) & $105 \pm 37$ & $104 \pm 32$ & $102 \pm 22$ & $104 \pm 28$ & $107 \pm 31$ & 0.128 \\
\hline \multicolumn{7}{|l|}{ Medication use, \% } \\
\hline ACE-inhibitors & 0.6 & 0.9 & 0.9 & 1.5 & 1.9 & 0.005 \\
\hline Beta-blockers & 0.3 & 0.4 & 0.9 & 0.7 & 0.5 & 0.427 \\
\hline Statin use & II & 14 & 15 & 16 & 19 & $<0.001$ \\
\hline Urinary albumin/creatinine ratio $(\mathrm{mg} / \mathrm{g})$ & $5.1[3.4,10.3]$ & $5.1[3.2,9.5]$ & $5.1[3.1,9.0]$ & $5.3[3.3,10.7]$ & $7.4[3.9,20.0]$ & $<0.001$ \\
\hline Serum cystatin $C(\mathrm{mg} / \mathrm{L})$ & $0.68 \pm 0.06$ & $0.77 \pm 0.02$ & $0.86 \pm 0.02$ & $0.96 \pm 0.03$ & $1.22 \pm 0.36$ & $<0.001$ \\
\hline Creatinine-based eGFR $\left(\mathrm{ml} / \mathrm{min} / 1.73 \mathrm{~m}^{2}\right)$ & $93 \pm 16$ & $87 \pm 15$ & $82 \pm 19$ & $77 \pm 13$ & $65 \pm 16$ & $<0.001$ \\
\hline
\end{tabular}

To convert $\mathrm{LDL}$ or HDL from $\mathrm{mg} / \mathrm{dL}$ to $\mathrm{mmol} / \mathrm{L}$, divide by 39 ; to convert glucose, divide by 18 ; to convert urinary albumin/creatinine ratio from $\mathrm{mg} /$ $\mathrm{g}$ to $\mathrm{mg} / \mathrm{mmol}$, multiply by $0.1 \mathrm{I}$; to convert serum creatinine from $\mathrm{mg} / \mathrm{dL}$ to $\mu \mathrm{mol} / \mathrm{L}$, multiply by 88 .

among persons with CKD were similar to the highest quintile of cystatin $\mathrm{C}$ in the entire cohort. Finally, adjusted linear regression models using cystatin $\mathrm{C}$ to predict biomarker levels were also examined for interactions by race/ethnicity. Statistically significant race/ethnicity interactions were found for the associations of cystatin $\mathrm{C}$ with CRP, IL-6, ICAM-1, and factor VIII (Table 4).

\section{Discussion}

Our analysis demonstrated that cystatin C was significantly correlated with all six procoagulant and inflammatory biomarkers across a broad range of kidney function, even after adjustment for age, gender, race/ethnicity, and BMI. While creatinine-based eGFR had significant correlations with all biomarkers except ICAM-1 in subjects with $\mathrm{CKD}$, it was only associated with TNF- $\alpha \mathrm{R} 1$ in participants without CKD. Adjusted mean levels of all biomarkers increased significantly across each quintile of cystatin C, and all biomarkers except ICAM- 1 were elevated in persons with eGFR $<60$ compared with eGFR $\geq 60$. In general, TNF- $\alpha \mathrm{R} 1$ had the strongest correlations with both cystatin $\mathrm{C}$ and eGFR in all groups.
Both creatinine-based eGFR and cystatin C correlated with most inflammatory markers in subjects with chronic kidney disease. However, in patients without CKD, only cystatin $\mathrm{C}$ had significant correlations with all markers of inflammation. There are several possible explanations for the association of cystatin $\mathrm{C}$ with procoagulant and inflammatory biomarkers in patients without chronic kidney disease. One possibility is that GFR is linearly associated with inflammation, and using cystatin $\mathrm{C}$, a marker of renal function that is less dependent on muscle mass or age, reveals the true association between kidney function and markers of inflammation when GFR is greater than 60 $\mathrm{mL} / \mathrm{min} / 1.73 \mathrm{~m}^{2}[22]$. Prior studies have shown that inflammatory markers are not associated with creatininebased eGFR above $60[8,9,16]$. However, this absence of association may be due to imprecision of eGFR in the normal range. A second explanation is that cystatin $\mathrm{C}$ is associated with inflammation independent of kidney function $[23,24]$. One study found that cystatin $\mathrm{C}$ was associated with CRP independent of creatinine clearance; however, that study did not have the gold standard of measured GFR [25]. Another study, also without a gold standard for GFR, found that the association between cystatin C and 
Table 2: Partial correlations of cystatin $C$ and creatinine-based eGFR with inflammatory and procoagulant markers at the baseline visit of the MESA study, stratified by presence of chronic kidney disease

\begin{tabular}{|c|c|c|c|c|c|c|}
\hline \multirow[t]{2}{*}{ Marker of Kidney Function } & \multicolumn{6}{|c|}{ Inflammatory Marker } \\
\hline & $\begin{array}{c}\text { CRP } \\
(N=6750)\end{array}$ & $\begin{array}{c}\text { IL-6 } \\
(N=6622)\end{array}$ & $\begin{array}{l}\text { TNF- } \alpha \mathrm{RI} \\
(\mathrm{N}=995)\end{array}$ & $\begin{array}{c}\text { ICAM-I } \\
(N=26 I I)\end{array}$ & $\begin{array}{l}\text { Fibrinogen } \\
(\mathrm{N}=6750)\end{array}$ & $\begin{array}{l}\text { Factor VIII } \\
(\mathrm{N}=6750)\end{array}$ \\
\hline Cystatin C & $0.075^{*}$ & $0.156^{*}$ & $0.748^{*}$ & $0.209 *$ & $0.137^{*}$ & $0.112^{*}$ \\
\hline Creatinine-based eGFR & -0.019 & -0.003 & $-0.285^{*}$ & 0.025 & $-0.059 *$ & $-0.034^{*}$ \\
\hline \multicolumn{7}{|l|}{ Persons with CKD } \\
\hline Cystatin C & $0.116^{*}$ & $0.230 *$ & $0.903^{*}$ & $0.160 *$ & $0.248^{*}$ & $0.140 *$ \\
\hline Creatinine-based eGFR & $-0.101 *$ & $-0.139 *$ & $-0.763 *$ & -0.035 & $-0.286 *$ & $-0.146 *$ \\
\hline \multicolumn{7}{|l|}{ Persons without CKD } \\
\hline Cystatin C & $0.085^{*}$ & $0.180^{*}$ & $0.557^{*}+$ & $0.26 I^{*}$ & $0.111 * t$ & $0.085^{*}$ \\
\hline Creatinine-based eGFR & $-0.004 \ddagger$ & $0.025 \ddagger$ & $-0.168^{*} \ddagger$ & 0.027 & $-0.021 \ddagger$ & $0.017 \ddagger$ \\
\hline
\end{tabular}

Partial correlations adjusted for age, gender, race/ethnicity, and BMI

Chronic kidney disease (CKD) defined as eGFR $<60 \mathrm{~mL} / \mathrm{min} / 1.73 \mathrm{~m}^{2}$

* Correlation is significant at the 0.01 level (2-tailed).

† Correlation between cystatin $C$ and the biomarker is significantly stronger among participants with CKD

$\ddagger$ Correlation between creatinine-based eGFR and the biomarker is significantly stronger among participants with CKD

CRP disappeared after adjustment for 24-hour urine creatinine clearance [16]. Our observation in this current study, that creatinine-based eGFR and cystatin C have similar associations with inflammatory markers among persons with CKD, makes it seem less likely that cystatin $\mathrm{C}$ has a direct association with inflammation that is independent of kidney function. However, our study also lacks a gold standard measurement of GFR, and therefore cannot be conclusive.

Both cystatin C and eGFR had substantial correlations with TNF- $\alpha$ R1, while the associations with the other inflammatory and procoagulant markers were more modest. In a murine model, one study demonstrated that ${ }^{125}$ Ilabeled soluble TNF receptors were primarily cleared by the mouse kidney [26]. In contrast, other inflammatory markers, such as CRP and IL-6, are primarily cleared by the liver $[27,28]$. While the strong association between kidney function and TNF- $\alpha$ R1 levels may be simply attrib- utable to renal clearance of TNF- $\alpha \mathrm{R} 1, \mathrm{TNF}-\alpha$ itself may also play a more complex role in the mediation of kidney damage. A future study should evaluate whether TNF- $\alpha$ and its soluble receptors predict the longitudinal progression of kidney disease.

A secondary goal of our analysis was to assess the role of race/ethnicity in the association between cystatin $\mathrm{C}$ and markers of inflammation. The association of four biomarkers - CRP, IL-6, ICAM-1, and factor VIII - with cystatin C had statistically significant interactions by race/ethnicity. Specifically, these four biomarkers had higher beta coefficients in whites compared with other races/ethnicities. One important issue is that, according to recent data, the assay used in MESA is only able to detect certain polymorphisms of ICAM-1 [29]. One allele in particular, ICAM-1 RS5491-T, is more common in African-Americans and not detected by the MESA assay. Further research is ongoing to evaluate the importance of polymorphisms on detection

Table 3: Adjusted mean biomarker levels at the baseline visit of the MESA study, in participants with and without chronic kidney disease

\begin{tabular}{|c|c|c|c|}
\hline Biomarker (units) & CKD Mean levels (95\% Cl) & No CKD Mean levels $(95 \% \mathrm{Cl})$ & P-value \\
\hline CRP $(\log \mathrm{mg} / \mathrm{L}) \mathrm{N}=6750$ & $0.8 \mathrm{I}(0.73,0.89)$ & $0.63(0.6 \mathrm{I}, 0.66)$ & $<0.001$ \\
\hline IL-6 (log pg/mL) N = 6622 & $0.37(0.33,0.4 I)$ & $0.19(0.18,0.21)$ & $<0.001$ \\
\hline TNF- $\alpha \mathrm{RI}(\mathrm{pg} / \mathrm{mL}) \mathrm{N}=995$ & $1.90(1.76,2.03)$ & $1.23(1.22,1.25)$ & $<0.001$ \\
\hline ICAM-I (ng/mL) N = 26I I & $281(27 I, 290)$ & $274(27 I, 277)$ & 0.19 \\
\hline Fibrinogen $(\mathrm{mg} / \mathrm{dL}) \mathrm{N}=6750$ & $363(360,372)$ & $345(343,346)$ & $<0.001$ \\
\hline Factor VIII (\%) N = 6750 & $187(181,193)$ & $161(160,163)$ & $<0.001$ \\
\hline
\end{tabular}

All biomarker models adjusted for age, gender, race/ethnicity, smoking status, BMI, diabetes, hypertension, LDL, HDL, and use of statins Chronic kidney disease (CKD) defined as eGFR $<60 \mathrm{~mL} / \mathrm{min} / 1.73 \mathrm{~m}^{2}$ 


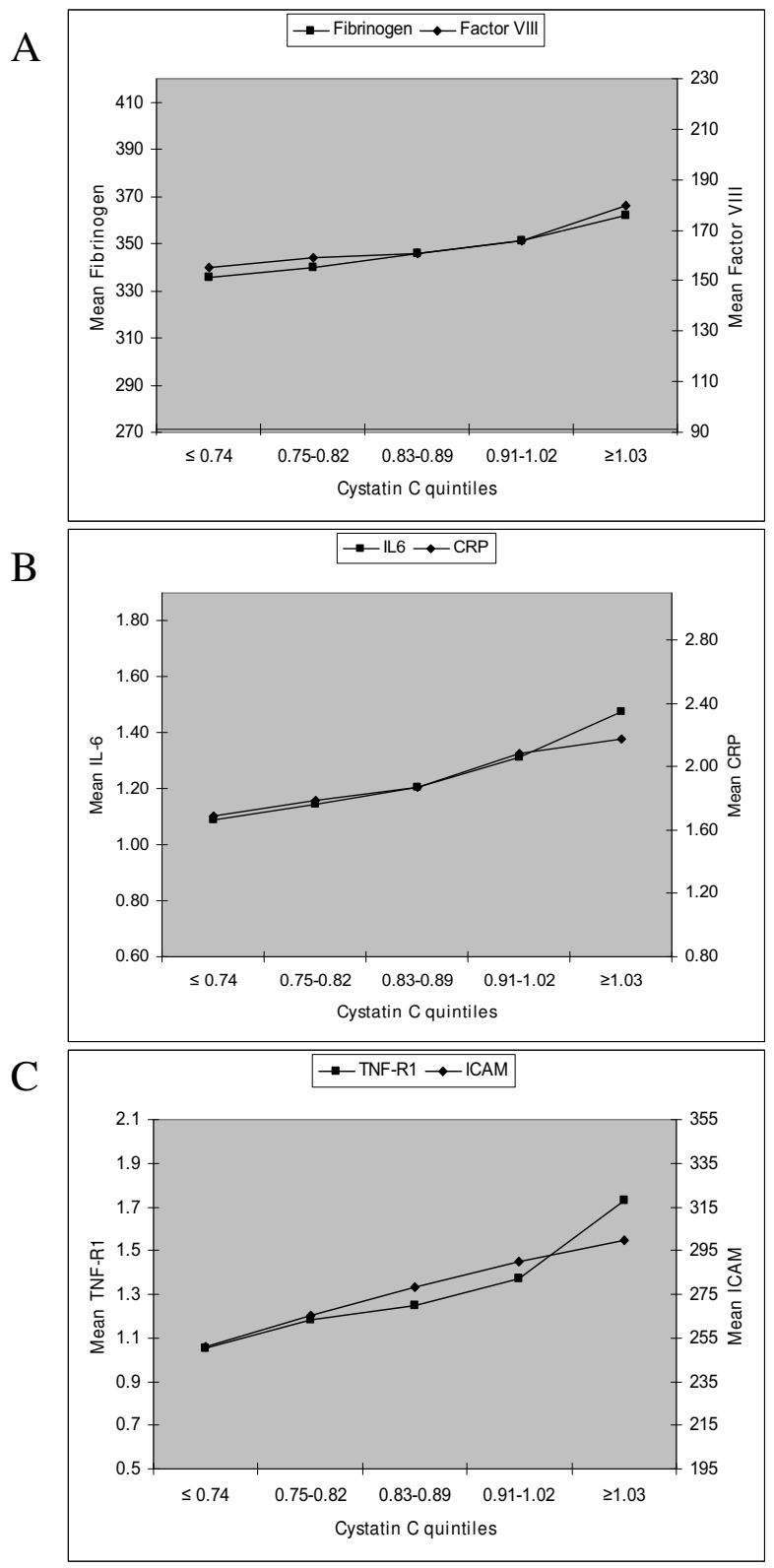

\section{Figure I}

Adjusted mean biomarkers by quintiles of cystatin $\mathbf{C}$ at the baseline visit of the MESA study. Models adjusted for age, gender, race/ethnicity, smoking status, body mass index, diabetes, hypertension, low-density lipoprotein, highdensity lipoprotein, use of statins, and log transformed urinary albumin to creatinine ratio. $Y$-axis scales are standardized to \pm 2 standard deviations of the overall mean of the cohort for TNF- $\alpha$ RI and \pm I standard deviation of the overall mean of the cohort for all other biomarkers.

of circulating markers of inflammation. In the MESA study, we are not aware of other assay issues that would affect the interpretation of race/ethnicity interactions with biomarkers.

One possible explanation for the interactions by race/ethnicity in cystatin $\mathrm{C}$ models is that regulation of inflammatory cytokines is more dependent on intact kidney function in whites than in other races/ethnicities. Prior studies have shown that CRP and fibrinogen levels are lower in whites than in African-Americans, and that whites at a given baseline level of CRP seem to have slower rises in serum creatinine over time compared with African-Americans [30-32]. These findings would suggest that whites may have a propensity for greater renal excretion of cytokines, although additional studies using urine measurements of cytokines may be helpful to evaluate these associations more effectively. Another explanation for these findings is that cystatin $\mathrm{C}$ is a better marker of GFR in whites versus other races/ethnicities. Overall, the association of cystatin C with GFR in non-white groups has not been well studied.

Our analysis has several limitations. First, while cystatin C has been conclusively demonstrated to be a reliable marker of kidney function, it may have associations with inflammation that are dependent of kidney function. Such associations would not be supported by this study, however, since we found that cystatin $\mathrm{C}$ and creatininebased eGFR had equally strong associations with inflammatory markers for subjects when eGFR $<60$. Second, as a cross-sectional study, we are unable to determine temporality in the association between cystatin $\mathrm{C}$ and multiple biomarkers. For example, inflammation may lead to declining kidney function, or reduced kidney function may lead to elevated inflammatory biomarkers. As stated above, we did not have a gold standard measurement for kidney function, such as iothalamate clearance. We also assumed that eGFR $<60$ was the appropriate cutpoint for chronic kidney disease for all subjects, although some data suggests that the established MDRD equation may need to be modified to more accurately characterize CKD race/ethnicity groups other than whites and AfricanAmericans [33].

\section{Conclusion}

We report significant associations between kidney dysfunction and markers of inflammation and procoagulation in a diverse population. Using cystatin C, associations were present in those with and without chronic kidney disease. Creatinine-based eGFR was similarly associated with these biomarkers primarily among subjects with CKD. These results suggest that markers of inflammation are progressively elevated as kidney function declines, even in subjects without chronic kidney disease. 
Table 4: Associations of cystatin $C$ and biomarker levels at the baseline visit of the MESA study using adjusted linear regression, stratified by race/ethnicity

\begin{tabular}{|c|c|c|c|c|c|}
\hline & $\begin{array}{l}\text { White } \beta \text { coefficient } \\
\qquad(95 \% \mathrm{Cl})\end{array}$ & $\begin{array}{l}\text { African-American } \beta \text { coefficient } \\
(95 \% \mathrm{Cl})\end{array}$ & $\begin{array}{c}\text { Chinese } \beta \text { coefficient } \\
(95 \% \mathrm{Cl})\end{array}$ & $\begin{array}{l}\text { Hispanic } \beta \text { coefficient } \\
(95 \% \mathrm{Cl})\end{array}$ & $\mathrm{p}$-value for interaction \\
\hline CRP (log mg/L) & $0.61(0.37,0.84)$ & $0.34(0.14,0.53)$ & $-0.12(-0.52,0.28)$ & $0.13(-0.06,0.31)$ & $<0.001$ \\
\hline IL-6 (log pg/mL) & $0.62(0.49,0.75)$ & $0.36(0.25,0.47)$ & $0.26(0.01,0.5 I)$ & $0.26(0.15,0.36)$ & $<0.001$ \\
\hline ICAM-I (ng/mL) & $100.4(78.8,122.0)$ & $66.2(18.7,113.7)$ & $30.8(-9.9,71.6)$ & $48.6(11.0,86.3)$ & 0.015 \\
\hline Factor VIII (\%) & $52.0(38.3,65.9)$ & $46.8(23.5,70.0)$ & $22.4(9.0,35.8)$ & $32.5(21.3,43.8)$ & 0.003 \\
\hline
\end{tabular}

All biomarker models adjusted for age, gender, race/ethnicity, smoking status, BMI, diabetes, hypertension, LDL, HDL, and use of statins. Beta coefficients are given per standard deviation of cystatin C

\section{List of abbreviations}

ANOVA: analysis of variance; BMI: body mass index; CKD: chronic kidney disease; CRP: C-reactive protein; CV: coefficients of variation; CVD: cardiovascular disease; ELISA: enzyme-linked immunosorbent assay; ESRD: end stage renal disease; eGFR: creatinine-based estimated glomerular filtration rate; GFR: glomerular filtration rate; ICAM-1: intercellular adhesion molecule-1; IL-6: interleukin-6; LDL: low-density lipoprotein; MDRD: Modification of Diet in Renal Disease; MESA: Multi-Ethnic Study of Atherosclerosis; SD: standard deviation; TNF- $\alpha$ : tumor necrosis factor alpha; TNF- $\alpha$ R1: tumor necrosis factor alpha receptor 1 .

\section{Competing interests}

The authors declare that they have no competing interests.

\section{Authors' contributions}

CK was the primary manuscript author and participated in the analysis design and overall data analysis. RK was the primary data analyst and also participated in analysis design and manuscript revision. MC participated in analysis design and manuscript revision. LFF participated in analysis design and manuscript revision. MS participated in the analysis design, overall data analysis, and manuscript revision. All authors have read and approved the final manuscript.

\section{Acknowledgements}

Dr. Keller is funded through a fellowship grant from the National Kidney Foundation. Dr. Shlipak is funded by ROI DK066488-0I, as well as by the American Heart Association Established Investigator Award. This research was also supported by contracts NOI-HC-95I59 through NOI-HC-95I69 from the National Heart, Lung, and Blood Institute (NHLBI). Cystatin C measurements were donated to the NHLBI by Dade Behring Inc., Deerfield, IL. A full list of participating MESA investigators and institutions can be found at http://www.mesa-nhlbi.org.

\section{References}

I. Pai JK, Pischon T, Ma J, Manson JE, Hankinson SE, Joshipura K, Curhan GC, Rifai N, Cannuscio CC, Stampfer MJ, et al.: Inflammatory markers and the risk of coronary heart disease in men and women. N Engl J Med 2004, 35 I (25):2599-26I0.

2. Ridker PM, Hennekens $\mathrm{CH}$, Buring JE, Rifai N: C-reactive protein and other markers of inflammation in the prediction of car- diovascular disease in women. N Engl J Med 2000, 342(I 2):836-843

3. Ridker PM, Rifai N, Stampfer MJ, Hennekens CH: Plasma concentration of interleukin- 6 and the risk of future myocardial infarction among apparently healthy men. Circulation 2000, I0I(15): 1767-1772.

4. Docci D, Bilancioni R, Buscaroli A, Baldrati L, Capponcini C, Mengozzi $\mathrm{S}$, Turci F, Feletti C: Elevated serum levels of C-reactive protein in hemodialysis patients. Nephron 1990, 56(4):364-367.

5. Herbelin A, Nguyen AT, Zingraff J, Urena P, Descamps-Latscha B Influence of uremia and hemodialysis on circulating interleukin-I and tumor necrosis factor alpha. Kidney Int 1990 37(I): I16-125.

6. Zimmermann J, Herrlinger S, Pruy A, Metzger T, Wanner C: Inflammation enhances cardiovascular risk and mortality in hemodialysis patients. Kidney Int 1999, 55(2):648-658.

7. Pecoits-Filho R, Barany P, Lindholm B, Heimburger O, Stenvinkel P: Interleukin-6 is an independent predictor of mortality in patients starting dialysis treatment. Nephrol Dial Transplant 2002, 17(9): 1684-1688.

8. Muntner P, Hamm LL, Kusek JW, Chen J, Whelton PK, He J: The prevalence of nontraditional risk factors for coronary heart disease in patients with chronic kidney disease. Ann Intern Med 2004, I 40(I):9-17.

9. Shlipak MG, Fried LF, Crump C, Bleyer AJ, Manolio TA, Tracy RP, Furberg $C D$, Psaty $B M$ : Elevations of inflammatory and procoagulant biomarkers in elderly persons with renal insufficiency. Circulation 2003, 107(1):87-92.

10. Coll E, Botey A, Alvarez L, Poch E, Quinto L, Saurina A, Vera M, Piera $C$, Darnell A: Serum cystatin $C$ as a new marker for noninvasive estimation of glomerular filtration rate and as a marker for early renal impairment. Am J Kidney Dis 2000, 36(I):29-34.

II. Perkins BA, Nelson RG, Ostrander BE, Blouch KL, Krolewski AS, Myers $B D$, Warram JH: Detection of renal function decline in patients with diabetes and normal or elevated GFR by serial measurements of serum cystatin C concentration: results of a 4-year follow-up study. I Am Soc Nephrol 2005, 16(5): 1404-1412

12. Randers E, Erlandsen EJ, Pedersen OL, Hasling C, Danielsen H: Serum cystatin $C$ as an endogenous parameter of the renal function in patients with normal to moderately impaired kidney function. Clin Nephrol 2000, 54(3):203-209.

13. Levey AS, Eckardt KU, Tsukamoto Y, Levin A, Coresh J, Rossert J, De Zeeuw D, Hostetter TH, Lameire N, Eknoyan G: Definition and classification of chronic kidney disease: a position statement from Kidney Disease: Improving Global Outcomes (KDIGO). Kidney Int 2005, 67(6):2089-2 I00.

14. Rule AD, Larson TS, Bergstralh E], Slezak JM, Jacobsen SJ, Cosio FG Using serum creatinine to estimate glomerular filtration rate: accuracy in good health and in chronic kidney disease. Ann Intern Med 2004, I 4 I ( I 2):929-937.

15. Keller CR, Odden MC, Fried LF, Newman AB, Angleman S, Green CA, Cummings SR, Harris TB, Shlipak MG: Kidney function and markers of inflammation in elderly persons without chronic kidney disease: the health, aging, and body composition study. Kidney Int 2007, 7 I (3):239-244.

16. Singh D, Whooley MA, Ix JH, Ali S, Shlipak MG: Association of cystatin $C$ and estimated GFR with inflammatory biomarkers: the Heart and Soul Study. Nephrol Dial Transplant 2007 22(4): 1087-1092. 
17. Erlandsen EJ, Randers E, Kristensen JH: Evaluation of the Dade Behring $\mathbf{N}$ Latex Cystatin $\mathbf{C}$ assay on the Dade Behring Nephelometer II System. Scand J Clin Lab Invest 1999, 59(I): I-8.

18. Levey AS, Coresh J, Balk E, Kausz AT, Levin A, Steffes MW, Hogg RJ, Perrone RD, Lau J, Eknoyan G: National Kidney Foundation practice guidelines for chronic kidney disease: evaluation, classification, and stratification. Ann Intern Med 2003, I39(2): I37-I 47.

19. Murthy K, Stevens LA, Stark PC, Levey AS: Variation in the serum creatinine assay calibration: a practical application to glomerular filtration rate estimation. Kidney Int 2005, 68(4): 1884-| 887.

20. Friedewald WT, Levy RI, Fredrickson DS: Estimation of the concentration of low-density lipoprotein cholesterol in plasma, without use of the preparative ultracentrifuge. Clin Chem 1972, 18(6):499-502.

21. Rosen BD, Cushman M, Nasir K, Bluemke DA, Edvardsen T, Fernandes V, Lai S, Tracy RP, Lima JA: Relationship between C-reactive protein levels and regional left ventricular function in asymptomatic individuals: the Multi-Ethnic Study of Atherosclerosis. J Am Coll Cardiol 2007, 49(5):594-600.

22. Randers E, Kristensen JH, Erlandsen EJ, Danielsen H: Serum cystatin $\mathbf{C}$ as a marker of the renal function. Scand J Clin Lab Invest 1998, 58(7):585-592.

23. Curhan G: Cystatin C: a marker of renal function or something more? Clin Chem 2005, 5 I (2):293-294.

24. Koenig W, Twardella D, Brenner H, Rothenbacher D: Plasma concentrations of cystatin $C$ in patients with coronary heart disease and risk for secondary cardiovascular events: more than simply a marker of glomerular filtration rate. Clin Chem 2005, 5 I (2):32I-327.

25. Knight EL, Verhave JC, Spiegelman D, Hillege HL, de Zeeuw D, Curhan GC, de Jong PE: Factors influencing serum cystatin C levels other than renal function and the impact on renal function measurement. Kidney Int 2004, 65(4): | 14|6-|42I.

26. Bemelmans $M H$, Gouma DJ, Buurman WA: Tissue distribution and clearance of soluble murine TNF receptors in mice. Cytokine 1994, 6(6):608-6I5.

27. Castell JV, Geiger T, Gross V, Andus T, Walter E, Hirano T, Kishimoto T, Heinrich PC: Plasma clearance, organ distribution and target cells of interleukin-6/hepatocyte-stimulating factor in the rat. Eur J Biochem 1988, I77(2):357-36I.

28. Hutchinson WL, Noble GE, Hawkins PN, Pepys MB: The pentraxins, $C$-reactive protein and serum amyloid $P$ component, are cleared and catabolized by hepatocytes in vivo. I Clin Invest 1994, 94(4): 1390-1396.

29. Register TC, Burdon KP, Lenchik L, Bowden DW, Hawkins GA, Nicklas BJ, Lohman K, Hsu FC, Langefeld CD, Carr J]: Variability of serum soluble intercellular adhesion molecule-I measurements attributable to a common polymorphism. Clin Chem 2004, 50(I I):2 I85-2I87.

30. Albert MA, Glynn RJ, Buring J, Ridker PM: C-reactive protein levels among women of various ethnic groups living in the United States (from the Women's Health Study). Am J Cardio 2004, 93( I 0): 1 238-1242.

31. Fried L, Solomon C, Shlipak M, Seliger S, Stehman-Breen C, Bleyer AJ Chaves $P$, Furberg C, Kuller L, Newman A: Inflammatory and prothrombotic markers and the progression of renal disease in elderly individuals. J Am Soc Nephrol 2004, I 5( I 2):3 184-3I9I.

32. Schutte AE, van Vuuren D, van Rooyen JM, Huisman HW, Schutte R, Malan L, Malan NT: Inflammation, obesity and cardiovascular function in African and Caucasian women from South Africa: the POWIRS study. J Hum Hypertens 2006, 20(II):850-859.

33. Ma YC, Zuo L, Chen JH, Luo Q, Yu XQ, Li Y, Xu JS, Huang SM, Wang $L N$, Huang $W$, et al:: Modified glomerular filtration rate estimating equation for Chinese patients with chronic kidney disease. J Am Soc Nephrol 2006, I 7( I 0):2937-2944.

\section{Pre-publication history}

The pre-publication history for this paper can be accessed here:

http://www.biomedcentral.com/1471-2369/9/9/prepub

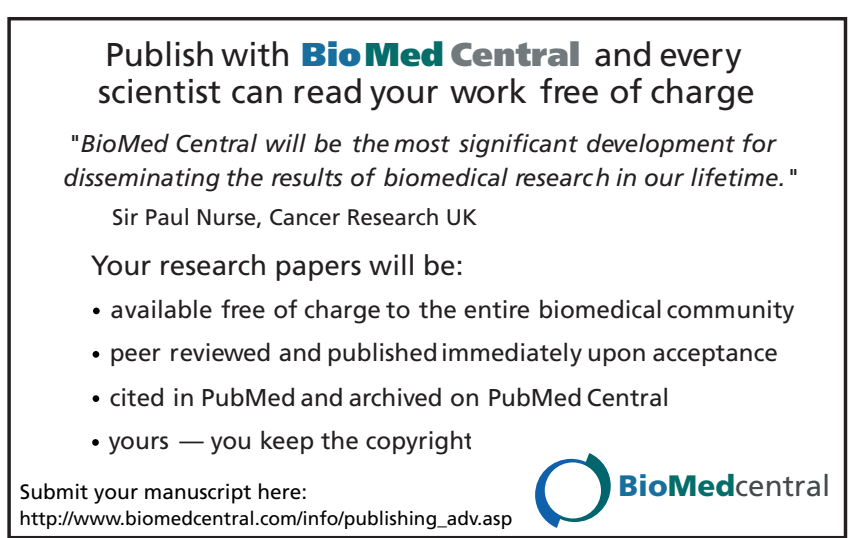

